\title{
Reliability of classification for post-traumatic ankle osteoarthritis
}

\author{
Femke M. A. P. Claessen ${ }^{1} \cdot$ Diederik T. Meijer ${ }^{2} \cdot$ Michel P. J. van den Bekerom $^{3}$ • \\ Barend D. J. Gevers Deynoot ${ }^{2} \cdot$ Wouter H. Mallee $^{2} \cdot$ Job N. Doornberg ${ }^{2} \cdot$ \\ C. Niek van Dijk ${ }^{4}$
}

Received: 30 January 2015 / Accepted: 10 November 2015 / Published online: 26 November 2015

(c) The Author(s) 2015. This article is published with open access at Springerlink.com

\begin{abstract}
Purpose The purpose of this study was to identify the most reliable classification system for clinical outcome studies to categorize post-traumatic-fracture-osteoarthritis.

Methods A total of 118 orthopaedic surgeons and residents-gathered in the Ankle Platform Study Collaborative Science of Variation Group-evaluated 128 anteroposterior and lateral radiographs of patients after a bi- or trimalleolar ankle fracture on a Web-based platform in order to rate post-traumatic osteoarthritis according to the classification systems coined by (1) van Dijk, (2) Kellgren, and (3) Takakura. Reliability was evaluated with the use of the Siegel and Castellan's multirater kappa measure. Differences between classification systems were compared using the two-sample $Z$-test.

Results Interobserver agreement of surgeons who participated in the survey was fair for the van Dijk osteoarthritis scale $(k=0.24)$, and poor for the Takakura $(k=0.19)$ and
\end{abstract}

Electronic supplementary material The online version of this article (doi:10.1007/s00167-015-3871-6) contains supplementary material, which is available to authorized users.

Femke M. A. P. Claessen

femke_claessen@hotmail.com

1 Orthopaedic Hand and Upper Extremity Service, Yawkey Centre, Massachusetts General Hospital, Harvard Medical School and University of Amsterdam Medical School, 55 Fruit Street, Boston, MA 02114, USA

2 Orthotrauma Research Centre Amsterdam, Academic Medical Centre Amsterdam, Amsterdam, The Netherlands

3 Orthopaedic Surgeon, Shoulder and Elbow Unit, Onze Lieve Vrouwe Gasthuis, Amsterdam, The Netherlands

4 Department of Orthopaedic Surgery, Academic Medical Centre Amsterdam, Amsterdam, The Netherlands the Kellgren systems $(k=0.18)$ according to the categorical rating of Landis and Koch. This difference in one categorical rating was found to be significant $(p<0.001$, CI $0.046-0.053$ ) with the high numbers of observers and cases available.

Conclusions This study documents fair interobserver agreement for the van Dijk osteoarthritis scale, and poor interobserver agreement for the Takakura and Kellgren osteoarthritis classification systems. Because of the low interobserver agreement for the van Dijk, Kellgren, and Takakura classification systems, those systems cannot be used for clinical decision-making.

Level of evidence Development of diagnostic criteria on basis of consecutive patients, Level II.

Keywords Ankle trauma - Post-traumatic ankle fracture osteoarthritis · Classification system · Interobserver study

\section{Introduction}

Radiographic evidence of osteoarthritis of the ankle may be associated with unsatisfactory ankle function. Osteoarthritis of the ankle joint varies based on aetiology (i.e. primary, secondary to inflammatory disease, or post-traumatic due to chronic instability, osteochondral defects, or post-fracture osteoarthritis), and radiographic appearance of degenerative changes might similarly differ based on the underlying condition $[1,35]$. It might be that radiographic appearances as well as reliability of current classification systems for osteoarthritis of the ankle joint vary depending on the aetiology of the degenerative changes [17, 31]. Only $79 \%$ of the optimally reduced ankle fractures showed good-to-excellent long-term outcome [30]. Post-traumatic osteoarthritis often seen after ankle fracture is dependent 
on several factors including fracture mechanism and joint instability [30, 33].

Classification systems exist to categorize radiographic signs of ankle osteoarthritis and could be useful to choose the most appropriate treatment and to predict the prognosis $[15,17,30,31]$. The Kellgren classification has been used for the radiographic staging of osteoarthritis of the peritalar joints. Fair interobserver agreement was found [19]. Van Dijk et al. showed a high percentage of good-to-excellent results after arthroscopic removal of anterior impingement lesions in grade 0 and I osteoarthritis. The results were unsatisfactory in grade II osteoarthritis lesions [34]. Tanaka et al. found good long-term outcomes after low tibial osteotomy in varus osteoarthritis of the ankle in stages II and III. Patients with stage III or stage IV ankle osteoarthritis had persistent loss of joint space [31]. These studies suggested that treatment and prognosis are dependent on the stage of ankle osteoarthritis. Post-traumatic ankle arthritis can be a very disabling condition, and therefore, adequate treatment is helpful.

The purpose of this study is to identify the most reliable classification system for clinical outcome studies to categorize post-traumatic-fracture-osteoarthritis. We did assess the reliability of the classification systems coined by (1) van Dijk, (2) Kellgren, and (3) Takakura for posttraumatic-fracture-osteoarthritis in an online interobserver study. We hypothesized that the van Dijk osteoarthritis scale, the Kellgren classification, and the Takakura scale are not reliable.

\section{Materials and methods}

The institutional research board (IRB) at the principal investigator's hospital approved this study for the use of anonymized radiographs.

\section{Patient characteristics}

Between 1974 and 2002, all patients with fractures that were treated with operative treatment in the Academic Medical Centre of Amsterdam, Level I trauma centre, were prospectively entered into a database according to the $\mathrm{AO} /$ OTA (Arbeitsgemeinschaft für Osteosynthesefragen/Orthopaedic Trauma Association) Comprehensive Classification of Fractures.

We identified a total of 437 AO/OTA-44 patients with fractures. Of these patients, 98 were deceased, 14 were classified as a cruris fracture, seven patients had an arthrodesis, five patients were considered mentally ill, three patients had a second fracture of the same ankle, one patient had an amputation of the affected leg, and one patient had a musculoskeletal disorder.
A total of 308 patients were eligible for long-term follow-up. Thirty-six patients were either emigrated or untraceable due to incorrect or outdated demographic data. The remaining 272 patients were invited for a long-term follow-up visit at our outpatient clinic. Of this group, 68 patients declined to participate in the study. Seventy-one patients did not respond and/or could not be contacted. A total of 133 patients participated in the study. The radiographs of five patients were not scored because the patients were not able to visit for follow-up radiographs. In total we included 128 patients in this study. Two patients had an AO/OTA type-A; one group A1, one group A2, zero group A3. Sixty-eight were AO/OTA type-B; zero group B1, zero group B2, 68 group B3 and there were 58 type 44-C fractures; nine group $\mathrm{C} 1,12$ group $\mathrm{C} 2$, and 37 group $\mathrm{C} 3$.

The median follow-up time of the included 128 patients was 23 years (range 13-39 years).

There were a total of 128 patients, including 67 women and 61 men with a median age of 40 years (range 14-68 years) at time of the accident. The median age at follow-up was 63 years (range 36-92 years).

The median body mass index was $27 \mathrm{~kg} / \mathrm{m}^{2}, 17(13 \%)$ patients had diabetes, and 33 (30\%) smoked.

A fall [61 (48\%)] was the most common trauma mechanism, followed by fall from height [29 (22\%)], sports related injuries [22 $(17 \%)$ ], traffic accident injuries [8 $(6 \%)$ ], and fall of heavy weight on ankle [8 (6\%)]

Twenty-one (16\%) patients had a high-energy injury, five (4\%) fractures were open, and six (5\%) patients did have an ipsilateral leg injury.

We classified the fractures with the AO/OTA classification: 44A1: one (1\%), 44A2: one (1\%), 44A3: zero, 44B1: zero, 44B2: zero, 44B3: 68 (53\%), 44C1: nine (7\%), 44C2: 12 (9\%), 44C3: 37 (29\%).

A total of 108 patients had a bimalleolar ankle fracture, and 20 patients had a trimalleolar ankle fracture.

Seven ankle fractures were complicated with a postoperative infection, two patients had thrombosis, and one patient had non-union. Hardware removal took place in 93 $(73 \%)$ of the patients.

\section{Study design}

Members of the Ankle Platform Study Collaborative Science of Variation Group were invited to evaluate 128 radiographs on a Web-based study platform (www.research. ankleplatform.com). All radiographs were weight bearing.

Each case had to be completed to continue with the next case. A total of 390 invitations were sent, and 150 members logged into our website. Observers were randomized to a custom Internet-based rating session with one of three set orders of cases (set order A, B, or C). A total of 118 observers completed the study (79\% of the initial responders). 
After logon, the observers were asked general information about their practice. Observers then had to grade radiographic signs of ankle osteoarthritis according to the van Dijk osteoarthritis score [34], Takakura classification scale [17], and Kellgren classification [15] (ESM Appendix I).

\section{Variables, outcome measures, data sources, and bias}

Independent variables were observer characteristics. Agreement among observers was determined using the multirater kappa measure described by Siegel and Castellan [27]. The multirater kappa measure is a frequently used statistical measure to describe chance-corrected agreement between ratings made by multiple observers (interobserver reliability) or between ratings made by one observer on multiple occasions (intra-observer reliability) [24]. The generated kappa values were interpreted according to the guidelines by Landis and Koch [18]: values of $0.010-0.20$ indicate poor agreements; $0.21-0.40$, fair agreement; $0.41-0.60$, moderate agreement; $0.61-0.80$, substantial agreement; and more than 0.81 , almost perfect agreement. Zero indicates no agreement beyond that expected resulting from chance alone, -1.0 means total disagreement, and +1.0 represents perfect agreement.

Classifications were compared using the two-sample $Z$-test, and $p$ values of $<0.050$ were considered significant $[2,4,6,7,10-14,20,32,36]$. A $Z$-test was also used to compare subgroups. For a more intuitive understanding of presented data and to control for kappa paradox, the proportion of agreement, defined as the proportion of observers agreeing with the most provided answer, was calculated for each case.

The only incentive for observers to participate was group authorship.

This protocol was approved by the IRB of the Academic Medical Centre of Amsterdam, the Netherlands, under protocol number 2013_214\#82013849.

\section{Statistical analysis}

Post hoc power analysis showed a power of $80 \%$ ( $a=0.05 ; B=0.20$ ), with 90 observers reviewing 128 patients in three randomized groups of at least 30 observers with 42 cases, respectively [10].

\section{Results}

\section{Participants}

A total of 118 observers (93\% male, $7 \%$ female) completed the online survey. A total of 37 observers participated in group A, 35 in group B, and 46 in group C. The
Table 1 Observer demographics $(n=118)$

\begin{tabular}{lc}
\hline Demographic & Number $(\%)$ \\
\hline Sex & \\
Male & $110(93)$ \\
Female & $8(7)$ \\
Area & \\
Asia & $16(14)$ \\
Australia & $1(1)$ \\
Continental Europe & $63(53)$ \\
U K & $9(8)$ \\
Other & $24(20)$ \\
USA & $5(4)$ \\
Years in practice & \\
$<5$ & $31(26)$ \\
$5-10$ & $37(31)$ \\
$11-20$ & $39(33)$ \\
$21-30$ & $8(7)$ \\
$>30$ & $3(3)$ \\
Involvement in resident training & \\
Yes & $92(78)$ \\
No & $26(22)$ \\
Number of ankle cases treated per year & \\
$0-5$ & $7(6)$ \\
$6-10$ & $7(6)$ \\
$11-20$ & $23(19)$ \\
$>30$ & $20(17)$ \\
\hline & $61(52)$ \\
\hline
\end{tabular}

majority of the observers who practised orthopaedics in continental Europe (53\%) were involved in resident training $(78 \%)$ and performed more than 30 ankle trauma surgeries a year $(52 \%)$ (Table 1). Only $6 \%$ of the observers treated five or less ankle fractures per year.

\section{Interobserver agreement}

The interobserver agreement between surgeons who participated in the survey was fair (reference value $0.21-0.40$ ) for the van Dijk osteoarthritis scale $(k=0.24)$, and poor (reference value 0.01-0.20) for the Takakura classification $(k=0.18)$ and the Kellgren osteoarthritis scale $(k=0.19)$ (Table 2). In absolute means, $61 \%$ agreement was achieved for the van Dijk osteoarthritis scale, $54 \%$ agreement for the Takakura classification, and $50 \%$ agreement for the Kellgren osteoarthritis scale.

Comparison of the van Dijk osteoarthritis scale to the Takakura classification revealed a significant difference of kappa values ( $p<0.001$, CI 0.046-0.053), as well as comparison to the Kellgren osteoarthritis scale $(p<0.001, \mathrm{CI}$ 
Table 2 Interobserver agreement classifications

\begin{tabular}{lll}
\hline Classification & Categorical & $k(n=118)$ \\
\hline Van Dijk & Fair agreement & 0.24 \\
Takakura & Poor agreement & 0.19 \\
Kellgren & Poor agreement & 0.18 \\
\hline
\end{tabular}

Table 3 Interobserver agreement for sex

\begin{tabular}{lllll}
\hline Classification & Categorical & $k 1(n=110)$ & Categorical & $k 2(n=8)$ \\
\hline Van Dijk & $\begin{array}{c}\text { Fair agree- } \\
\text { ment }\end{array}$ & 0.24 & $\begin{array}{c}\text { Poor agree- } \\
\text { ment }\end{array}$ & 0.090 \\
Takakura & $\begin{array}{c}\text { Fair agree- } \\
\text { ment }\end{array}$ & 0.22 & $\begin{array}{c}\text { Poor agree- } \\
\text { ment }\end{array}$ & 0.17 \\
Kellgren & $\begin{array}{c}\text { Poor agree- } \\
\text { ment }\end{array}$ & 0.18 & $\begin{array}{c}\text { Poor agree- } \\
\text { ment }\end{array}$ & 0.10 \\
\hline
\end{tabular}

$1=$ male 2 = female

0.056-0.064) with the high numbers of observers and cases included in this study.

\section{Factors associated with interobserver agreement}

Poor-to-fair agreement was found for sex of the observers, years in practice, number of ankle fractures treated per year, involvement in resident training (Tables 3, 4, $5,6)$. No particular factors increased the interobserver agreement. There was no significant difference between 5-10 years in practice and 11-20 years in practice for the van Dijk classification $(p=1.0)$. The interobserver agreement was not significantly higher with increasing numbers of ankle fractures treated per year for any of the classifications. There was a higher agreement in observers who are involved in resident training for all classifications $(p<0.001)$.
Table 6 Interobserver agreement for involvement in resident training

\begin{tabular}{lllll}
\hline Classification & Categorical & $k 1$ & Categorical & $k 2$ \\
\hline Van Dijk & Fair agreement & 0.24 & Poor agreement & 0.20 \\
Takakura & Fair agreement & 0.24 & Poor agreement & 0.16 \\
Kellgren & Poor agreement & 0.19 & Poor agreement & 0.13 \\
\hline
\end{tabular}

$1=$ yes; $2=$ no

\section{Discussion}

The most important finding of the present study was that the reliability of the van Dijk osteoarthritis scale, the Kellgren classification, and the Takakura scale was low.

Treatment and prognosis of post-traumatic-fractureosteoarthritis of the ankle are suggested to be dependent on the stage of degenerative changes in the ankle joint [23, 31, 34, 35]. Therefore, reliable classification systems are important as they should guide treatment or prognosis to facilitate clinical decision-making and to compare patient cohort studies in the literature [28].

In this interobserver study, we did search for the most reliable classification system for post-traumatic-fracture-osteoarthritis. We did assess the reliability of the van Dijk osteoarthritis scale, the Kellgren classification, and the Takakura scale [15, 31, 34].

The strengths of this interobserver study include the large number of observers, which allowed randomization and subgroup analysis to increase the generalizability of the results. However, it should be interpreted in the light of several limitations. We have not studied a variety of potential sources of variation, including cultural differences, standardized training of observers, and computer and screen quality. This study was limited to interobserver agreement only because intra-observer agreement is less relevant to clinical practice as surgeons mostly agree with

Table 4 Interobserver agreement for years in practice

\begin{tabular}{lllllllllll}
\hline Classification & Categorical & $k 1$ & Categorical & $k 2$ & Categorical & $k 3$ & Categorical & $k 4$ & Categorial & $k 5$ \\
\hline Van Dijk & Fair agreement & 0.31 & Fair agreement & 0.23 & Fair agreement & 0.24 & Fair agreement & 0.21 & Fair agreement & 0.31 \\
Takakura & Fair agreement & 0.26 & Fair agreement & 0.21 & Fair agreement & 0.24 & Poor agreement & 0.10 & Poor agreement & 0.010 \\
Kellgren & Poor agreement & 0.18 & Fair agreement & 0.28 & Fair agreement & 0.21 & Poor agreement & 0.090 & Fair agreement & 0.22 \\
\hline
\end{tabular}

$1=<5 ; 2=5-10 ; 3=11-20 ; 4=21-30 ; 5=>30$

Table 5 Interobserver agreement for number of ankle fractures treated per year

\begin{tabular}{lllllllllll}
\hline Classification & Categorical & $k 1$ & Categorical & $k 2$ & Categorical & $k 3$ & Categorical & $k 4$ & Categorial & $k 5$ \\
\hline Van Dijk & Fair agreement & 0.30 & Fair agreement & 0.25 & Fair agreement & 0.25 & Poor agreement & 0.20 & Fair agreement & 0.25 \\
Takakura & Fair agreement & 0.27 & Fair agreement & 0.24 & Fair agreement & 0.23 & Poor agreement & 0.14 & Fair agreement & 0.23 \\
Kellgren & Poor agreement & 0.15 & Fair agreement & 0.21 & Fair agreement & 0.17 & Poor agreement & 0.17 & Poor agreement & 0.18 \\
\hline
\end{tabular}

$1=0-5 ; 2=6-10 ; 3=11-20 ; 4=21-30 ; 5=>30$ 
themselves and not so much with each other. In our survey, we did not find factors that increased interobserver agreement. We have not included patients that had an arthrodesis, and therefore, the patients in our cohort might have less severe arthrosis.

Interobserver agreement of the surgeons who participated in the survey was only fair for the van Dijk osteoarthritis scale $(k=0.24)$, and poor for the Takakura classification $(k=0.18)$ and Kellgren osteoarthritis scale $(k=0.19)$ (Table 2). Although the van Dijk osteoarthritis scale was significantly more reliable than the other classifications, the clinical relevance of this difference is debatable, because the interobserver agreement is low. Interestingly, more years of experience resulted in a higher interobserver agreement for all classifications; however, the number of treated ankle fractures per year did not influence interobserver agreement.

Since treatment and prognosis of post-traumaticfracture-osteoarthritis of the ankle are suggested to be dependent on its stage [23,31,34, 35], reliable classification systems are helpful. In early stages, non-surgical treatment options such as anti-inflammatory medications or braces are often used [23, 35]. The main surgical treatment options include arthroscopic debridement and osteophyte resection, ankle osteotomy, total ankle prosthesis (TAP), and arthrodesis [3, 5, 8, 9, 21, 22, 25, 26, 29, 31, 34]. Arthroscopic debridement and osteophyte resection are recommended in mild osteoarthritis [8], and osteotomy is preferred in mild-to-moderate osteoarthritis with tibiotalar malalignment [29]. In end-stage osteoarthritis, TAP and arthrodesis are the treatment options of preference $[3,5$, $21,22,26,35]$.

Several classification systems should be compared to choose the most reliable classification system to prevent treatment variation. Krause et al. [16] tested the postoperative Canadian Orthopaedic Foot and Ankle Society end-stage ankle arthritis classification system in patients operated for end-stage ankle arthritis. This classification identifies no deformity, intra-articular deformity, extraarticular deformity, and surrounding joint arthritis. An almost perfect agreement was found $(k=0.89)$. A possible explanation for the higher interobserver agreement compared to our study could be the use of the Canadian Orthopaedic Foot and Ankle Society end-stage ankle arthritis classification system in end-stage ankle osteoarthritis patients only. Moreover, four observers evaluated 60 cases. The low number of observers can result in a higher kappa. Moreover, identifying osteoarthritis characteristics is much easier than identifying different stages of osteoarthritis that do not easily fall into categories.

Consistent with our study, the Kellgren and Lawrence osteoarthritis scale did show to be fair for classifying the degree of osteoarthritis present in the subtalar joint $(k=0.21)$ and talonavicular joint $(k=0.25)$ [19]. Treatment variation is unwanted in medical practice, and therefore, classification systems should have a high interobserver agreement to be reliable.

Van Dijk et al. described good-to-excellent results after arthroscopic removal of anterior impingement lesion lowgrade osteoarthritis. The results were unsatisfactory in higher osteoarthritis lesions [34]. Tanaka et al. [31] found persistent loss of joint space in higher-stage ankle osteoarthritis compared to early stage ankle osteoarthritis.

\section{Conclusions}

This study documents fair interobserver agreement for the van Dijk osteoarthritis scale, and poor interobserver agreement for the Takakura and the Kellgren osteoarthritis classification systems. Because of the low reliability of all three investigated classification systems in this study and a substantial percentage of surgeons who disagreed, those classifications cannot be used in day-to-day practice in terms of clinical decision-making. Easier classifications with fewer categories might result in higher reliability and are therefore more valuable for clinical practice.

Ankle Platform Study Collaborative: Science of Variation Group P Filho, J.H. Davenport, T.S. Roukis, P. Spennacchio, N. Dreiangel, I. Frangez, I. Bissell, C.J.A. van Bergen, N. Moreno, N. Martinelli, B. Clair, F. Guy, R. Miller, C.P. Marquis, J. Batista, S. Verfaillie, C. Plaass, P.L.Guidi, S. Kapoor, S. Bahari, B. Patczai, A. Toom, P. Hemmingsson, V. Stevanovic, P. Sicchiero, N. Darabos, P. Symeonidis, P.N.F. Ferrao, R. Marinescu, N. Atallah Yurdi, D. Park, S. Al-Nammari, Alireza, G.D. Carpeggiani, E.C. Pasion, D. Sá da Costa, L.Keiserman, E.J. Yeap, A.L.R. Souza, G. Martinho, S. Becirbegovic F. Milian, R. Freihaut, G. Bulstra, A. Burg, M. P. van den Bekerom, M. Orduña-Moncusí, P. Greyling, N. Koukoulias, P.H. Ousema, M.J. Kumar, R.P. Walter, Kanellos P, M.P.A. Bus, G.H. Naderi, D. Verbeek, G. Sulkers, W. Gang, J. Abdeloihab, V.A.R. de Miranda, J.R. Lansdaal, S. El Hage, C.M. van Dijk, S. Hingelbaum, Kourosh, T.M. Bajenescu, R. Zambelli, A.R. Hsu, H. Weel, G. Laval, G. Daguerre, L. La Verde, H. Benea, P. Ceccarini, A.J.C Ramos, V. Kecojević, F. Lijoi, A.R. Gaspar, M. Breccia, M. Aulamo, H. Pereira, L. Laver, T. Klos, C.A.Borbon, E. Palmanovich, A. Engvall, A.A.L. Moraes, A. Ajis, I. Yoshimura, D. Haverkamp, H. Pereira, A. Russo, C.R. Cortes, K. Kaliyaperumal, V. Pasters, M.C.M. Dinato, P.S. Jayaprasad, H. Kurup, G. Bakhtamyan, P. Zbikowski, H. Haapasalo, E. Baca, L.W. van der Plaat, A. Abdelwahab, S. Chandrashekar, A. Grauls, A.J. Kievit, D. Baumfeld, I. Bojanic, A. Marmotti, N.G.Y.C. S, A. Correia Moreira D.E. Hatziemmanuil, A.D. Mora, G. Pánics, M. Tomco, D.H. Kim, D.J. Caldarella, M.R. Sousa, O.C. Aragon, J. Torrent, H. Tanaka, Abigail Finger.

\section{Compliance with ethical standards}

Conflict of interest DT. Meijer and J.N. Doornberg have received an unrestricted research grant from the Marti-Keuning Eckhart Foundation. F.M.A.P Claessen has received a research grant from the Prins Bernhard Cultuur foundation, Trust foundation, VSB foundation, and Van Beek-Donner foundation. For the remaining authors, none were declared. 
Open Access This article is distributed under the terms of the Creative Commons Attribution 4.0 International License (http://creativecommons.org/licenses/by/4.0/), which permits unrestricted use, distribution, and reproduction in any medium, provided you give appropriate credit to the original author(s) and the source, provide a link to the Creative Commons license, and indicate if changes were made.

\section{References}

1. Barg A, Pagenstert GI, Hugle T, Gloyer M, Wiewiorski M, Henninger HB, Valderrabano V (2013) Ankle osteoarthritis: etiology, diagnostics, and classification. Foot Ankle Clin 18(3):411-426

2. Bruinsma WE, Guitton TG, Warner JJ, Ring D, Science of Variation G (2013) Interobserver reliability of classification and characterization of proximal humeral fractures: a comparison of two and three-dimensional CT. J Bone Joint Surg Am 95(17):1600-1604

3. Buchner M, Sabo D (2003) Ankle fusion attributable to posttraumatic arthrosis: a long-term followup of 48 patients. Clin Orthop Relat Res 406:155-164

4. Buijze GA, Guitton TG, van Dijk CN, Ring D, Science of Variation $G$ (2012) Training improves interobserver reliability for the diagnosis of scaphoid fracture displacement. Clin Orthop Relat Res 470(7):2029-2034

5. Coester LM, Saltzman CL, Leupold J, Pontarelli W (2001) Long-term results following ankle arthrodesis for post-traumatic arthritis. J Bone Joint Surg Am 83-A(2):219-228

6. Doornberg JN, Guitton TG, Ring D, Science of Variation G (2013) Diagnosis of elbow fracture patterns on radiographs: interobserver reliability and diagnostic accuracy. Clin Orthop Relat Res 471(4):1373-1378

7. Doring AC, Hageman MG, Mulder FJ, Guitton TG, Ring D, Science of Variation G (2014) Trigger finger: assessment of surgeon and patient preferences and priorities for decision making. $\mathbf{J}$ Hand Surg Am 39(11):2208-2213 (e2202)

8. Fitzgibbons TC (1999) Arthroscopic ankle debridement and fusion: indications, techniques, and results. Instr Course Lect 48:243-248

9. Gross AE, Agnidis Z, Hutchison CR (2001) Osteochondral defects of the talus treated with fresh osteochondral allograft transplantation. J Foot Ankle Surg 22(5):385-391

10. Guitton TG, Ring D, Science of Variation G (2011) Interobserver reliability of radial head fracture classification: two-dimensional compared with three-dimensional CT. J Bone Joint Surg Am 93(21):2015-2021

11. Hageman MG, Becker SJ, Bot AG, Guitton T, Ring D, Science of Variation G (2013) Variation in recommendation for surgical treatment for compressive neuropathy. J Hand Surg Am 38(5):856-862

12. Hageman MG, Guitton TG, Ring D, Science of Variation G (2013) How surgeons make decisions when the evidence is inconclusive. J Hand Surg Am 38(6):1202-1208

13. Hageman MG, Jayakumar P, King JD, Guitton TG, Doornberg JN, Ring D, Science of Variation G (2015) The factors influencing the decision making of operative treatment for proximal humeral fractures. J Shoulder Elbow Surg 24(1):e21-e26

14. Hageman MG, Kinaci A, Ju K, Guitton TG, Mudgal CS, Ring D, Science of Variation G (2014) Carpal tunnel syndrome: assessment of surgeon and patient preferences and priorities for decision-making. J Hand Surg Am 39(9):1799-1804 (e1791)

15. Kellgren JH, Lawrence JS (1957) Radiological assessment of osteo-arthrosis. Ann Rheum Dis 16(4):494-502

16. Krause FG, Di Silvestro M, Penner MJ, Wing KJ, Glazebrook MA, Daniels TR, Lau JT, Younger AS (2012) The postoperative
COFAS end-stage ankle arthritis classification system: interobserver and intraobserver reliability. Foot Ankle Spec 5(1):31-36

17. Lambers KT, van den Bekerom MP, Doornberg JN, Stufkens SA, van Dijk CN, Kloen P (2013) Long-term outcome of pronationexternal rotation ankle fractures treated with syndesmotic screws only. J Bone Joint Surg Am 95(17):e1221-e1227

18. Landis JR, Koch GG (1977) The measurement of observer agreement for categorical data. Biometrics 33(1):159-174

19. Mayich DJ, Pinsker E, Mayich MS, Mak W, Daniels TR (2013) An analysis of the use of the Kellgren and Lawrence grading system to evaluate peritalar arthritis following total ankle arthroplasty. J Foot Ankle Surg 34(11):1508-1515

20. Mellema JJ, Doornberg JN, Guitton TG, Ring D, Science of Variation G (2014) Biomechanical studies: Science (f)or common sense? Injury 45(12):2035-2039

21. Newton SE 3rd (1982) Total ankle arthroplasty. Clinical study of fifty cases. J Bone Joint Surg Am 64(1):104-111

22. Nihal A, Gellman RE, Embil JM, Trepman E (2008) Ankle arthrodesis. J Foot Ankle Surg 14(1):1-10

23. Patzkowski JC, Owens JG, Blanck RV, Kirk KL, Hsu JR, Skeletal Trauma Research C (2012) Management of posttraumatic osteoarthritis with an integrated orthotic and rehabilitation initiative. J Am Acad Orthop Surg 20(Suppl 1):S48-S53

24. Posner KL, Sampson PD, Caplan RA, Ward RJ, Cheney FW (1990) Measuring interrater reliability among multiple raters: an example of methods for nominal data. Stat Med 9(9):1103-1115

25. Raikin SM (2009) Fresh osteochondral allografts for large-volume cystic osteochondral defects of the talus. J Bone Joint Surg Am 91(12):2818-2826

26. Saltzman CL, Mann RA, Ahrens JE, Amendola A, Anderson RB, Berlet GC, Brodsky JW, Chou LB, Clanton TO, Deland JT, Deorio JK, Horton GA, Lee TH, Mann JA, Nunley JA, Thordarson DB, Walling AK, Wapner KL, Coughlin MJ (2009) Prospective controlled trial of STAR total ankle replacement versus ankle fusion: initial results. J Foot Ankle Surg 30(7):579-596

27. Siegel S, Castellan NJ (eds) (1988) Nonparametric statistics for the behavioral sciences. McGraw-Hill

28. Smith RM (2000) The classification of fractures. J Bone Joint Surg Br 82(5):625-626

29. Stamatis ED, Cooper PS, Myerson MS (2003) Supramalleolar osteotomy for the treatment of distal tibial angular deformities and arthritis of the ankle joint. J Foot Ankle Surg 24(10):754-764

30. Stufkens SA, van den Bekerom MP, Kerkhoffs GM, Hintermann B, van Dijk CN (2011) Long-term outcome after 1822 operatively treated ankle fractures: a systematic review of the literature. Injury 42(2):119-127

31. Tanaka Y, Takakura Y, Hayashi K, Taniguchi A, Kumai T, Sugimoto K (2006) Low tibial osteotomy for varus-type osteoarthritis of the ankle. J Bone Joint Surg Br 88(7):909-913

32. Tosti R, Ilyas AM, Mellema JJ, Guitton TG, Ring D, Science of Variation G (2014) Interobserver variability in the treatment of little finger metacarpal neck fractures. J Hand Surg Am 39(9):1722-1727

33. van den Bekerom MP, Haverkamp D, Kloen P (2009) Biomechanical and clinical evaluation of posterior malleolar fractures. A systematic review of the literature. J Trauma 66(1):279-284

34. van Dijk CN, Verhagen RA, Tol JL (1997) Arthroscopy for problems after ankle fracture. J Bone Joint Surg Br 79(2):280-284

35. Weatherall JM, Mroczek K, McLaurin T, Ding B, Tejwani N (2013) Post-traumatic ankle arthritis. Bull Hosp Jt Dis 71(1):104-112

36. Wijffels MM, Guitton TG, Ring D, Science of Variation G (2012) Inter-observer variation in the diagnosis of coronal articular fracture lines in the lunate facet of the distal radius. Hand 7(3):271-275 